\title{
Methodical support for investigation of system behaviour by means of analysis techniques-overcoming non-transparency in embodiment design
}

\author{
Kevin Hölz ${ }^{1}$ (D) Patric Grauberger ${ }^{1}$ (D) S Sven Matthiesen ${ }^{1}$ (D) \\ Received: 23 December 2019 / Accepted: 5 September 2020 / Published online: 28 September 2020 \\ (c) The Author(s) 2020
}

\begin{abstract}
One challenge in adaptive design of technical systems is insufficient understanding of the mechanical system behavior. The actual system behaviour often differs from the system behaviour expected by the designer. This is due, for example, to influences from manufacturing, wear, or errors in the designer's understanding. For the analysis of the differences between expected and actual system behavior, the system behaviour can be observed. Special analysis techniques are often necessary for system observation. However, the missing methodical support in the system-specific use of analysis techniques is a challenge. In this contribution, a methodical support for the selection and adaptation of analysis techniques for system observation is developed. For this, known errors that occur during system observation are operationalised and provided as requirements for evaluation of analysis techniques. The support is provided as a Selection Matrix, in which the evaluated analysis techniques can be selected and adapted. This is evaluated considering an accompanying application to the non-transparent system wood screw connection. By using the analysis techniques selected with the method, it was possible to identify the actual system behaviour and gain new insights. Here, the Selection Matrix provided support through a structured evaluation of analysis techniques. The Selection Matrix also supported the adaptation of analysis techniques for improved observation of the system behaviour. No general statements on the quality of the support by the Selection Matrix are yet possible. Also, the operationalisation of the errors should be improved to reduce subjective influences. Therefore, these topics should be investigated in further studies.
\end{abstract}

Availability of data and material Some or all data, that support the findings of this study are available as supplementary files.

Sven Matthiesen

sven.matthiesen@kit.edu

1 IPEK - Institute of Product Engineering, Karlsruhe Institute of Technology (KIT), Karlsruhe, Germany 


\section{Methodische Unterstützung zur Systemanalyse mit Hilfe von Analysetechniken - Überwindung von Intransparenz in der Gestaltung}

\section{Zusammenfassung}

Eine Herausforderung bei der Weiterentwicklung technischer Systeme ist ein unzureichendes Verständnis des mechanischen Systemverhaltens. Das tatsächliche Systemverhalten weicht häufig von dem durch den Konstrukteur erwarteten Systemverhalten ab. Dies liegt beispielsweise an Einflüssen aus der Fertigung, dem Verschleiß oder an Fehlern im Verständnis des Konstrukteurs. Für die Analyse der Abweichung zwischen erwartetem und tatsächlichen Systemverhalten, kann das Systemverhalten beobachtet werden. Für die Systembeobachtung sind häufig spezielle Analysetechniken notwendig. Die fehlende methodische Unterstützung bei der systemspezifischen Anwendung von Analysetechniken ist jedoch eine Herausforderung. In diesem Beitrag wird eine methodische Unterstützung für die Auswahl und Anpassung von Analysetechniken für die Systembeobachtung entwickelt. Dazu werden bekannte Fehler, die bei der Systembeobachtung auftreten, operationalisiert und als Anforderungen an Analysetechniken für die Bewertung bereitgestellt. Die Unterstützung wird durch eine Auswahlmatrix bereitgestellt, in welcher die bewerteten Analysetechniken ausgewählt und angepasst werden können. Diese wird entwicklungsbegleitend am intransparenten System Holzschraubverbindung evaluiert. Durch die mit der Methode ausgewählten Analysetechniken war es möglich, das tatsächliche Systemverhalten zu identifizieren und neue Erkenntnisse zu gewinnen. Hier unterstützte die Auswahlmatrix durch die strukturierte Bewertung von Analysetechniken. Auch die Anpassung von Analysetechniken zur besseren Beobachtung des Systemverhaltens wurde durch die Auswahlmatrix unterstützt. Es sind noch keine allgemeinen Aussagen zur Qualität der Unterstützung durch die Auswahlmatrix möglich. Zudem sollte die Operationalisierung der Fehler weiter verbessert werden, um subjektive Einflüsse zu reduzieren. Daher sollten diese Themen in weiterführenden Studien untersucht werden.

\section{Introduction}

The process of designing is based on iterative sequences of analysis and synthesis steps [1]. Causes for iterations often are unknown design problems. In order to solve them, an analysis must be performed to find out whether the available information is sufficient to understand them [2]. In adaptive design and reverse engineering, questions about design details are in focus [3]. Here, analysis of the mechanical behaviour of the preceding system or high-fidelity prototypes is often necessary to gain insights for successful design. The understanding of the system behaviour is essential for the further development.

The actual behaviour can differ from the system behaviour expected by the designer, for example, due to wear or manufacturing influences. The product's structure must be analysed to identify the behaviour derived from it [4]. This analysis is often difficult to conduct [5], as the behaviour of the product results from interactions in its embodiment and also from its interaction with the system environment [3]. It is often only possible to identify faults and weak points in the design by observing the product under application conditions [6].

Simulations are quite common in these kinds of investigations of system behaviour. However, they often lack in suitable details. In conceptual design, the evaluation of design issues uses approximate calculations and assessments to investigate the performance of an evolving concept [7]. For these calculations, however, the behaviour derived from structure and the resulting effects must be known. In some cases (e.g. unknown material characteristics or friction effects), it is not possible to predict exactly how components will interact in operation and what effects this may have on the overall system [8]. This may be due to unknown causes for system behaviour. Here, the physical product embodiment must also be investigated in experiments due to unknown properties [9]. In setting up an experiment, it is recommended to consult experts that can support through their understanding of the system [10]. In the case of reverse engineering, however, experts for the investigated details are often not available. Moreover, if experts have different opinions and hypotheses on how the system behaves, experimental investigations reach a limit, as it is no longer sufficient to only measure behaviour (e.g. through force sensors).

Observation of the mechanical product embodiment under application conditions is needed to derive behaviour from the structure. Here, observation means the purposeful investigation of system behaviour through qualitative methods, which can be applied directly (e.g. high-speed videos) or indirectly (e.g. CT scan). The challenge here lies in observing the right thing, which enables the formulation of hypotheses. Without suitable analysis methods, derivation of purposeful hypotheses becomes difficult. Based on these hypotheses, tests or experiments can be conducted that lead to the necessary insights. 
Fig. 1 Application of analysis techniques to drywall screws. a Wear marks, b marking ink [16]
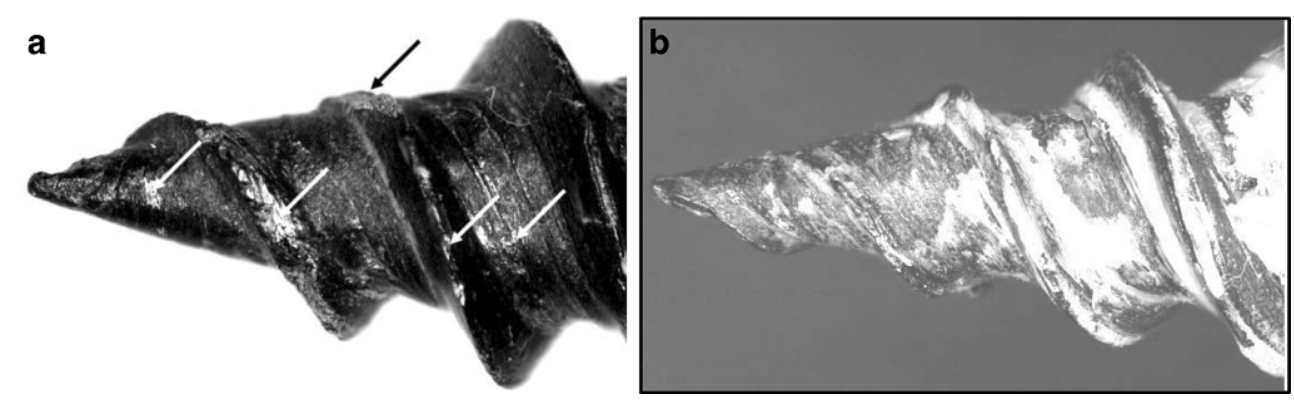

\subsection{Non-transparency in analysis}

When observing system behaviour, different errors can occur. ZANKER distinguishes the following three classes of errors that can occur when observing a system [11]: Information not available, faulty observation, and incorrect interpretation. For a purposeful analysis, these errors should be considered and, if possible, excluded.

The error class information not available includes the basic challenge of non-transparency, as parts of a system are not directly observable and/or not directly accessible [8]. Through this, a barrier hinders observation of interactions in technical systems [12]. When an observation barrier occurs, necessary insights are missing and therefore design must rely on assumptions as to which embodiment parameters influence the function and behaviour (embodiment function relation-EFR). In these non-transparent systems, verification of the assumptions of EFRs is difficult. Falsified assumptions often lead to iterations which delay the development process [13, 14]. In product development, verification through analysis is necessary for conducting synthesis-driven analysis [15], which aims at the synthesis of an improved product.

Only when non-transparency is overcome, it is possible to address the error classes of faulty observation or incorrect interpretation. A challenge emerges in how to carry out a purposeful observation of the product behaviour, as this is not described in the literature mentioning the necessity of observation in analysis.

\subsection{Overcoming non-transparency in analysis}

One way of overcoming non-transparency in analysis is the use of heuristics [12]. They are often understood as $\operatorname{cog}$ nitive shortcuts which result from successful and intuitive procedures and experiences [16-18]. However, heuristics do not guarantee successful solutions [19]. They need to be implemented in analysis techniques to be able to apply them to a problem. An example of a heuristic is surface analysis, where the surface of a component is analysed for contact points in order to identify function-relevant areas, or the so-called working surface pairs [9]. The surface analysis can be implemented with the following analysis techniques [16]:

- Contact points: Search for points of contact of two surfaces to identify working surface pairs (direct observation).

- Wear marks: Wear marks are evidence that a component has been in contact with a solid, liquid or a gas (indirect observation).

- Marking ink: visualisation of the contact points of surfaces by surface treatment, e.g. colour (indirect observation).

For the described analysis techniques, the application to the drywall screw system is shown in Fig. 1.

The analysis technique wear marks is shown in Fig. 1a. The identified wear marks of a drywall screw are marked with arrows. This wear shows working surfaces between screw and ground. In Fig. 1b, the analysis technique marking ink is shown. A white marking paint is applied to a drywall screw which is then screwed in. Working surfaces are visible as areas where the white paint has been scratched off. Furthermore, there are other analysis techniques, such as the in-situ model by HORN ET AL. for determining the failure processes of chemical anchors [20], and UIBEL's technique for observing the behaviour of a wood screw connection during the screwing process [21]. All of these analysis techniques are system-specific. Additionally, THAU captured a vast variety of analysis techniques for synthesisdriven analysis [16].

However, the missing methodical support in how to use analysis techniques remains a challenge. Often, several analysis techniques have to be combined or adapted [16]. Suitable analysis techniques for the system are implicitly selected by the designers. The selection of suitable analysis techniques is a difficulty [22], as it remains unclear when and which analysis technique is to be used for a specific situation [16].

Therefore, the objective of this contribution is to develop and evaluate a methodical support for the systematic selection and adaptation of analysis techniques in order to observe the mechanical behaviour of non-transparent systems. 
This methodical support is developed as a structure that will enable the evaluation of existing analysis techniques as well as their combination into new analysis techniques suitable for specific tasks. A matrix approach in the form of the below presented Selection Matrix is chosen. It is evaluated by an application to a non-transparent system in Sect. 3.

\section{Selection matrix}

A Selection Matrix is developed to provide methodical support for the selection of analysis techniques. In order to develop the matrix, categories for classification of certain aspects of the analysis techniques are required. Therefore, in the first step, the error classes for system observation by ZANKER [11] are operationalised as requirements for analysis techniques. This is described in Sect. 2.1. These requirements are then transferred into a Selection Matrix in the second step. The final matrix is then presented in Sect. 2.2.

\subsection{Operationalisation of the error classes}

In the following, requirements for evaluation of the analysis techniques are derived. These requirements focus on the application to mechanical systems and are based on the three error classes by ZANKER [11].

Requirements for the first error class Information not available are derived through the categories used by THAU [16]. The categories include: identification of functions, working surface pairs, channel and support structure, and combination of function and embodiment. The category channel and support structure describes function-relevant volumes of the embodiment that connect working surface pairs [23].

- Observable system behaviour. This requirement describes the identification of functions. According to WINTERGERST, the area of function fulfilment must be observable [12]. The system behaviour can be observed at any point in time, at different points in time, or continuously throughout. "To gain knowledge about a systems parameters and their [sic] relation to the dynamic behaviour, the differentiation of its behaviour into states can be used" [24, p. 4]. The requirement of observable system behaviour is that the area of function fulfilment must be observable at different times or timecontinuously.

- Observable contact. This requirement describes the identification of function-relevant embodiment (working surface pairs and channel and support structures) and thus the spatial observation of the area of function ful- filment. The necessity of observing the contact results directly from non-transparency.

- Combination with measurement data. In order to be able to quantify information gained from observation, a combination of system parameters (embodiment), observations (real behaviour, qualitative), and quantitative experimental data is necessary [22]. To enable this link, it must be possible to collect this data.

The second error class faulty observation describes the errors resulting from the observation itself. The following requirements can be formulated:

- Minimal change in behaviour. The system is usually modified in order to enable observation of system behaviour. Hence, the changes made should influence the behaviour as little as possible [22]. This is quite difficult and has to be evaluated e.g. through the comparison of system behaviour.

- Minimal contact change. In order to make the embodiment observable, the system often has to undergo a considerable change. This change can lead to geometric or material changes or even material exchange in the contact area.

The third error class incorrect interpretation describes errors that can occur when assumptions about EFRs are inferred from the observation. The following requirements can be formulated for this error class:

- Reproducible effect. In order to verify assumptions about EFR, the effect of a parameter variation must be examined. A causal effect is reproducible and describes the effect of a system change on system performance [10].

- Visible effect strength. For the effect strength, it is necessary that the change of an embodiment parameter is larger than the scatter of the system to be observed. This can be described as a necessity to observe a sufficient number of appropriate state variables [25].

\subsection{Development of the selection matrix based on requirements}

The aim of the Selection Matrix is the purposeful evaluation and combination of existing analysis techniques. It is designed as a situation-specific support for investigation of unknown mechanical system behaviour, e.g. in adaptive design. The two-dimensional core element of the Selection Matrix is shown in Fig. 2a. The error classes and requirements for each error class are shown in the first dimension. These are listed line by line. The analysis techniques to be evaluated are to be noted in columns and include the second dimension. The matrix is structured similarly to other 
Fig. 2 Selection Matrix for the selection and adaptation of analysis techniques (a), and process for using the matrix (b) a

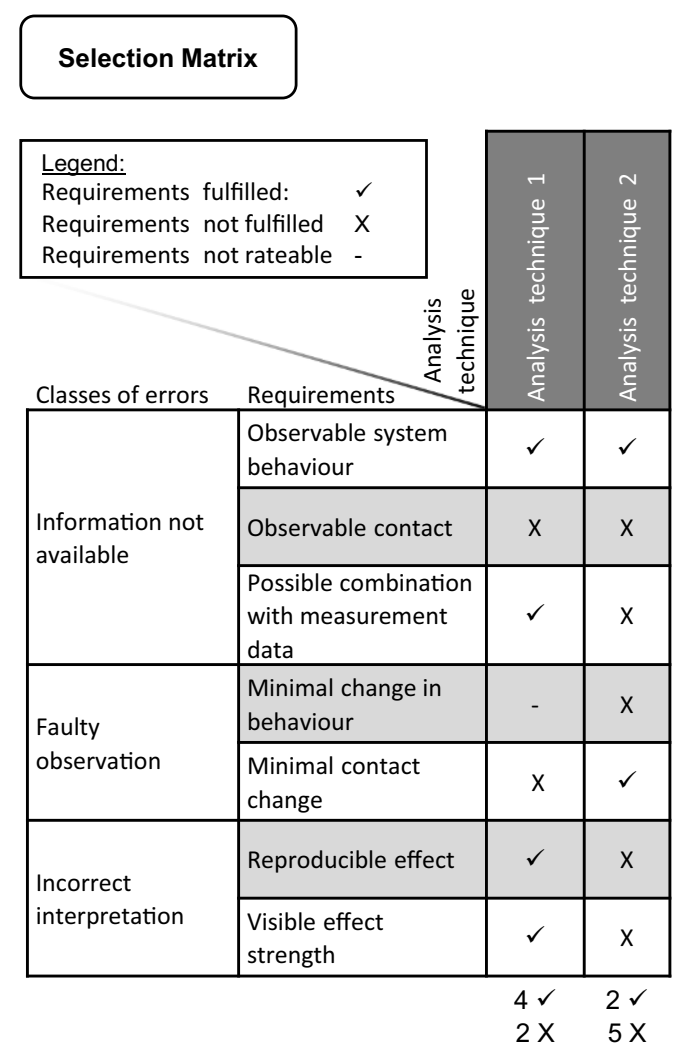

b
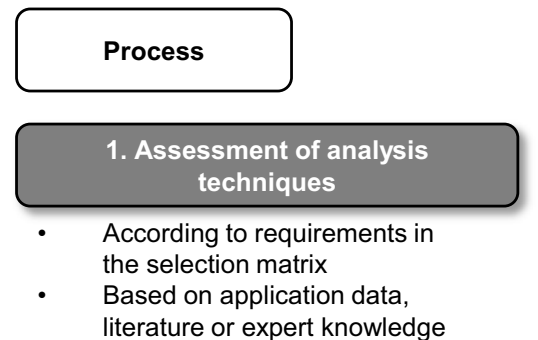

2. Selection by comparison

- Fulfillment of requirements

- Comparison of strengths and weaknesses

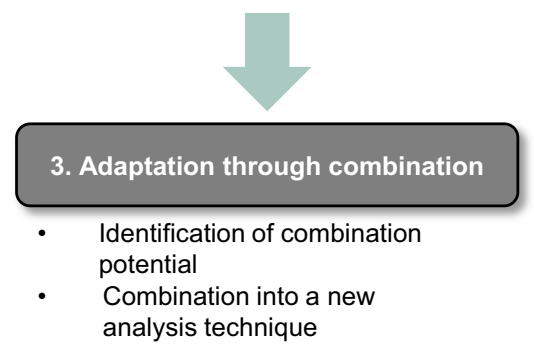

known methods, such as the Pugh Matrix [26] for the selection of concepts.

Fig. 2b shows the process for using the Selection Matrix. First, the analysis techniques are assessed according to the requirements and then they are integrated into the Selection Matrix. The fulfilment of the requirements is assessed on the basis of application data, literature, and expert knowledge. An analysis technique can fulfil a requirement $(\boldsymbol{V})$ or not fulfil it $(\mathrm{X})$. It is also possible that a requirement cannot not be rated (-). For each analysis technique, the sum of fulfil and not fulfil can be calculated at the end of the column.

Secondly, various analysis techniques can be compared on the basis of the sum of fulfilled and unfulfilled requirements. From this, potentially suitable analysis techniques can be selected. Here, the Selection Matrix also serves as documentation of possibly resource-intensive decisions.

Thirdly, analysis techniques can be adapted by identifying possible combinations of themselves. The Selection Matrix allows comparison of the fulfilment of single requirements of different analysis techniques to eliminate individual weak points. Thus, it is possible to adapt analysis techniques to a specific situation. This aims at increasing the chance to observe mechanical system behaviour which is unknown in detail and for which no suitable analysis techniques have been existing so far. The application area of the Selection Matrix is limited to mechanical systems.

\section{Accompanying application in the development of the selection matrix}

The Selection Matrix was evaluated using an accompanying application. Here, the system wood screw connection was chosen as a non-transparent system. The interaction between wood and screw is not readily visible and difficult to conceive for design engineers. Due to the anisotropic and porous material properties of wood, scatter caused by natural growth processes [27], and different failure scenarios [28], the wood screw connection shows a complex system behaviour and, therefore, is a suitable system for the application and evaluation of the presented Selection Matrix.

The Selection Matrix is applied in a development project which aimed at the synthesis-driven analysis of wood screws through understanding of the failure behaviour of a wood screw connection. This aim requires the selection of suitable analysis techniques. The project was supported by an industrial supplier of self-tapping screws. The duration of the project was approximately 15 months. Six product managers as well as design engineers from the fields of mechanical engineering, civil engineering, and 
timber construction were involved. The application of the Selection Matrix was conducted by the authors. The results were presented and discussed in workshops with the other project participants. Within the context of the project, many analysis techniques were tested and a total of 250 pull-out tests were carried out to select and evaluate them. By applying the analysis techniques recommended by the Selection Matrix, it was possible to identify previously unknown system behaviours of wood screw connections [29].

\subsection{Assessment of analysis techniques}

In the following, the assessment of six analysis techniques is presented to clarify the application steps of the Selection Matrix. Fig. 3 shows the application and the assessment of the analysis techniques to fulfil the requirement observable contact. The headline shows the analysis techniques applied. The bottom line shows the application of the analysis technique to the wood screw connection and the evaluation of the requirement.

The analysis technique marking ink is used for surface treatment of the wood screw. This is because no visible wear is expected with wood screws due to the high difference in hardness in the contact screw-wood. As shown in Fig. 3a, the red marking ink was almost entirely removed from the surface of the screw and adheres to all surfaces in the wood. The contact of the screw with the wood cannot be narrowed down further, and the observation is made more difficult by the applied ink. Thus, no additional observation is possible, and the requirement observable contact is not fulfilled.

The analysis technique $X$-Ray is applied by computer tomography to a wood-screw connection. In Fig. 3b, the X-ray image of a screw connection can be seen in section through the screw axis. The image shows black bars pointing away from the screw. This effect is called 'beam hardening', and is an error in X-raying that results from the high density difference between the metal screw and the wood. Due to this physical phenomenon, the contact between the wood screw and the wood cannot be investigated further since no details can be observed in this area. Therefore, the requirement observable contact is not fulfilled.

A simpler analysis technique is video recording. Here, the pull-out process of the wood screw was recorded with a video camera (Fig. 3c). The behaviour during pull-out can be observed time-continuously. The contact between the screw and the wood is still not visible, the requirement observable contact is not fulfilled. However, the requirement observable system behaviour is fulfilled.

Another analysis technique is the creation of sectional models. A sectional model was created contactlessly using a $\mathrm{CO} 2$ laser. The wavelength of the $\mathrm{CO} 2$ laser is well suited for cutting wood whilst metal screws are not affected. An area of the screw connection is lasered parallel to the screw axis. However, Fig. 3d shows that some parts of the wood are well removed, whereas the laser shows little effect on the annual rings. This is due to the differences in density between spring wood and annual rings. Thus, no clear $o b$ servation of the contact is possible, and the requirement is not fulfilled.

Another sectional model is produced by saw machining of wood. As shown in Fig. 3e, a $90^{\circ}$ section of the wood is removed with a saw before the screw is applied. The wood screw is then screwed into the resulting corner and pulled out. The contact is observable at the two interfaces between the screw and the wood, exactly on the left and right sides of the corner, although wood chips cover the picture. Despite occurring challenges in the application, observation is possible. Hence, the requirement observable contact is fulfilled. However, the requirement minimal contact change is

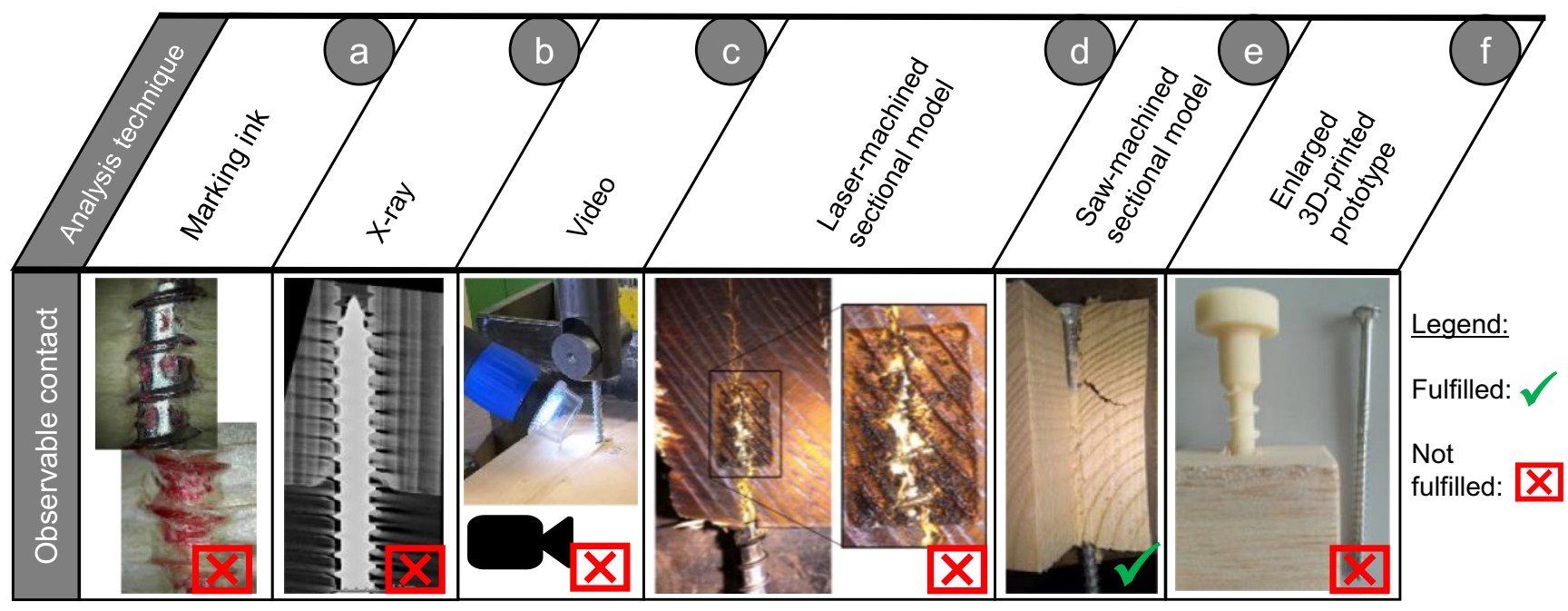

Fig. 3 Application of analysis techniques to the wood screw connection for evaluation of the requirement observable contact 
Fig. 4 Selection Matrix for systematic evaluation of analysis techniques

\begin{tabular}{|c|c|c|c|c|c|c|c|c|}
\hline \multicolumn{2}{|c|}{$\begin{array}{l}\text { Legend: } \\
\text { Requirement fulfilled: } \\
\text { Requirement not fulfilled: } \quad \text { X } \\
\text { Requirement not rateable: - }\end{array}$} & \multirow{2}{*}{ 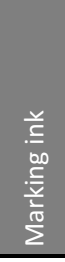 } & \multirow{2}{*}{$\frac{\sqrt{0}}{\frac{\pi}{x}}$} & \multirow{2}{*}{$\frac{8}{\frac{0}{0}}$} & \multirow{2}{*}{ 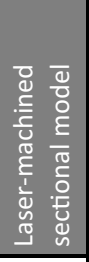 } & \multirow{2}{*}{ 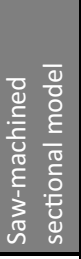 } & \multirow{2}{*}{ 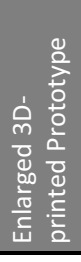 } & \multirow{2}{*}{ 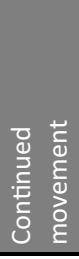 } \\
\hline Classes of errors & Requirements & & & & & & & \\
\hline \multirow{3}{*}{$\begin{array}{l}\text { Information not } \\
\text { available }\end{array}$} & $\begin{array}{l}\text { Observable system } \\
\text { behaviour }\end{array}$ & $\mathrm{x}$ & - & $\checkmark$ & - & $\checkmark$ & $\checkmark$ & $\checkmark$ \\
\hline & Observable contact & $x$ & $x$ & $x$ & $x$ & $\checkmark$ & $x$ & $\checkmark$ \\
\hline & $\begin{array}{l}\text { Possible combination } \\
\text { with measurement } \\
\text { data }\end{array}$ & $\checkmark$ & $\checkmark$ & $\checkmark$ & $\checkmark$ & $\checkmark$ & $\checkmark$ & $\checkmark$ \\
\hline \multirow{2}{*}{$\begin{array}{l}\text { Faulty } \\
\text { observation }\end{array}$} & $\begin{array}{l}\text { Minimal change in } \\
\text { behaviour }\end{array}$ & - & $\checkmark$ & $\checkmark$ & - & - & $x$ & $\checkmark$ \\
\hline & $\begin{array}{l}\text { Minimal contact } \\
\text { change }\end{array}$ & $x$ & $\checkmark$ & - & - & $\mathrm{x}$ & $x$ & $x$ \\
\hline \multirow{2}{*}{$\begin{array}{l}\text { Incorrect } \\
\text { interpretation }\end{array}$} & Reproducible effect & $\checkmark$ & $\checkmark$ & $\checkmark$ & $x$ & $x$ & $\checkmark$ & $\checkmark$ \\
\hline & $\begin{array}{l}\text { Visible effect } \\
\text { strength }\end{array}$ & $\mathrm{X}$ & $x$ & $x$ & $x$ & $\checkmark$ & $\checkmark$ & $\checkmark$ \\
\hline & & $2 \checkmark$ & $4 \checkmark$ & $4 \checkmark$ & $1 \checkmark$ & $4 \checkmark$ & $4 \checkmark$ & $6 \checkmark$ \\
\hline & & $4 x$ & $2 x$ & $2 x$ & $3 x$ & $2 x$ & $3 x$ & $1 x$ \\
\hline & & & & $\downarrow$ & & $\downarrow$ & & 4 \\
\hline
\end{tabular}

not fulfilled, and further investigation into how the system behaviour changes through the contact change is necessary.

The analysis technique enlarging prototypes is often suitable for the identification of areas of functional fulfilment as it makes very large systems manageable for the designers. For this purpose, a wood screw is manufactured from ABS material by $3 D$ printing (Fig. 3f) using the fused deposition modelling process. The wood screw is manufactured in a ratio of $2: 1$ to the real screw, and is screwed into the wood and then pulled out. The wood is not scaled, as scaling needs a very great effort in reproducing the anisotropic parameters. Results showed that the necessary tensile strength could not be reached with the printed ABS screws. Therefore, the requirement minimal change in behaviour is not fulfilled. The contact between the screw and the wood is still not visible, and the requirement observable contact is not fulfilled.

With this application data, the applied analysis techniques are also evaluated against the other requirements mentioned in Sect. 2.1. The complete evaluation can be found as research data under https://doi.org/10.5445/IR/ 1000123853. The results are presented in the following section.

\subsection{Comparison and adaptation of analysis techniques through the selection matrix}

The evaluation of the analysis techniques for the wood screw connection is transferred into the Selection Matrix and presented in Fig. 4.

The matrix shows that the analysis technique laser-machined sectional model with one fulfilled requirement and three unfulfilled requirements performed the worst. Furthermore, the analysis techniques $X$-Ray, Video, and $3 D$ print are rated as most helpful, with four fulfilled requirements and two unfulfilled requirements each. Moreover, the ability for combinations has become evident. One possible combination is the analysis technique Video with Saw-machined sectional model, in which the weaknesses of each technique are compensated and the strengths are made usable. The analysis technique adapted by the combination is called continued movement. This technique uses the possibility to observe the contact of screw thread and wood and combines it with time-continuous data acquisition by using video microscopy. In the video analysis, the behaviour of the wood in the failure of the contact becomes visible.

The application to the wood screw connection shows that the requirements allow an evaluation where the analysis techniques can be differentiated. One exception is the requirement combination with measurement data, which was fulfilled with all analysis techniques. This allows for 
weighting of the analysis techniques and thus a final selection of the most reasonable technique through the Selection Matrix. Furthermore, it could be shown that by comparing the strengths and weaknesses of the analysis techniques, it is possible to adapt them and find suitable combinations. The matrix shows further possible combinations of other analysis techniques; however, not all combinations of analysis techniques will be possible.

\section{Discussion}

The Selection Matrix can extend the state of the art where designers must intuitively decide which analysis technique to select. In the application, the possibility of adaptation by the combination of analysis techniques was shown. This supports the thesis by THAU [16] that often, several analysis techniques have to be combined.

Since the evaluation is carried out on the basis of criteria for error classes in system observation, it can be assumed that other heuristics and analysis techniques can also be evaluated. Further analysis techniques of non-transparent systems can be integrated into the Selection Matrix. For the assessment, the analysis techniques must be applied on a test basis. If the matrix has already been existing, e.g. for previous generations, it can also be used for similar products in earlier product development phases such as the conceptual design phase. The experiences from the completed matrix can be transferred to other systems. For example, density differences in materials is problematic for the X-ray technique. This not only applies to the wood screw connection but can also be generalised.

The objective of the contribution was to provide methodological support for the observation of non-transparent systems. This has been reached in the following aspects:

- The matrix allows for structured evaluation of analysis techniques. The requirements allow an evaluation where the analysis techniques can be differentiated.

- A systematic selection becomes possible by comparing the sum of fulfilled and unfulfilled requirements. This allows to select potentially suitable analytical techniques.

- The adaptation of analysis techniques becomes possible through combination based on the identified strengths and weaknesses. The matrix offers the possibility to compare the fulfilment of individual requirements of the analysis techniques and thus to determine potential combination possibilities.

Limitations to this investigation are the operationalisation of the error classes. The requirements derived from the error classes are a first step towards the evaluation of analysis techniques; however, their quantitative rateability must be improved, as up to now, subjective evaluation still shows a certain influence. One research approach would be a multiple case study. The analysis of observations of different systems allows to specify the requirements for the selection of analytical techniques and thus to improve the quality of the operationalisation. It can also be checked whether a weighting of the requirements is necessary and possible. If it is possible, a net score can then be calculated by subtracting the unfulfilled requirements from the number of fulfilled requirements. A similar procedure for working with a selection matrix is shown by ULRICH AND EPPINGER [30]. This net score allows a ranking of the analysis techniques. Since a possible weighting of the requirements is still unclear, no net score can be calculated at the moment. For more generalised statements on the quality of support of the Selection Matrix, further studies of other non-transparent systems and also investigations into its applicability for design engineers are necessary.

\section{Conclusion and outlook}

There are different analysis techniques by means of which the mechanical system behaviour can be observed in adaptive design. Thus, actual, unknown system behaviour can be identified. The challenge is to evaluate analysis techniques and to select a suitable one for the specific case. For the evaluation of analysis techniques, error classes of system observation are operationalised and provided as requirements. These requirements are integrated into a Selection Matrix for selection of suitable analysis techniques. The assessment of analysis techniques against the requirements in the Selection Matrix allows the selection. By comparing the strengths and weaknesses, the Selection Matrix also allows the adaptation and further development of analysis techniques. The result of the investigation is a Selection Matrix for the systematic selection and adaptation of analysis techniques, which provides methodical support for design engineers. It is evaluated in an accompanying application of a wood screw connection as a non-transparent system.

In further research, the Selection Matrix will be evaluated on other non-transparent systems. This allows more general statements on the quality of support. The operationalisation shows need for further research to reduce subjective influences.

Acknowledgements The authors would like to thank the company Adolf Würth $\mathrm{GmbH} \&$ Co. KG for the joint work in this research project. This research was supported by the Research Centre for Steel, Timber and Masonry, Karlsruhe Institute of Technology (KIT).

Funding The investigations of the wood screw connections were funded by Adolf Würth GmbH \& Co. KG. These investigations were supported by the Research Centre for Steel, Timber and Masonry, Karlsruhe Institute of Technology (KIT). 
Funding Open Access funding enabled and organized by Projekt DEAL.

Conflict of interest K. Hölz, P. Grauberger and S. Matthiesen declare that they have no competing interests.

Open Access This article is licensed under a Creative Commons Attribution 4.0 International License, which permits use, sharing, adaptation, distribution and reproduction in any medium or format, as long as you give appropriate credit to the original author(s) and the source, provide a link to the Creative Commons licence, and indicate if changes were made. The images or other third party material in this article are included in the article's Creative Commons licence, unless indicated otherwise in a credit line to the material. If material is not included in the article's Creative Commons licence and your intended use is not permitted by statutory regulation or exceeds the permitted use, you will need to obtain permission directly from the copyright holder. To view a copy of this licence, visit http://creativecommons.org/licenses/by/4. $0 \%$.

\section{References}

1. Lossack R-S (2006) Wissenschaftstheoretische Grundlagen für die rechnerunterstützte Konstruktion. Springer, Berlin Heidelberg

2. Fiorineschi L, Rotini F, Rissone P (2016) A new conceptual design approach for overcoming the flaws of functional decomposition and morphology. J Eng Des 27(7):438-468. https://doi.org/10. 1080/09544828.2016.1160275

3. Matthiesen S (2020) Prozess und Methoden der Gestaltung. In: Bender B, Gericke K (eds) Pahl/Beitz Konstruktionslehre, 9th edn. Springer, Berlin Heidelberg

4. Gero JS (1990) Design prototypes: a knowledge representation schema for design. Ai Mag 11(4):26. https://doi.org/10.1609/ aimag.v11i4.854

5. Hutterer P (2005) Reflexive Dialoge und Denkbausteine für die methodische Produktentwicklung. Dissertation. Technische Universität München, München

6. Lindemann U (2009) Methodische Entwicklung technischer Produkte. Springer, Berlin, Heidelberg

7. Kroll E, Weisbrod G (2020) Testing and evaluating the applicability and effectiveness of the new idea-configuration-evaluation (ICE) method of conceptual design. Res Eng Design 31(1):103-122. https://doi.org/10.1007/s00163-019-00324-6

8. Badke-Schaub P, Frankenberger E (2004) Management Kritischer Situationen. Springer, Berlin Heidelberg

9. Ehrlenspiel K, Meerkamm H (2017) Integrierte Produktentwicklung, 6th edn. Hanser, München

10. Siebertz K, van Bebber D, Hochkirchen T (2010) Statistische Versuchsplanung. Springer, Heidelberg

11. Zanker W (1999) Situative Anpassung und Neukombination von Entwicklungsmethoden. In: Lindemann U (ed) Konstruktionstechnik München. Dissertation, vol 36. Shaker, Aachen

12. Wintergerst E (2015) Leitfaden zur deduktiven Gestaltvariation durch Ermittlung der funktionsbestimmenden Stellgrößen in der Produktgenerationsentwicklung. In: Albers A (ed) Forschungsberichte IPEK. Dissertation, vol 86. Karlsruher Institut für Technologie (KIT), Karlsruhe

13. Meboldt M, Matthiesen S, Lohmeyer Q (2012) The dilemma of managing iterations in time-to-market development processes. In: Heisig P (ed) 2nd international workshop on modelling and management of engineering processes MMEP, pp 127-139
14. Wynn DC, Eckert CM (2017) Perspectives on iteration in design and development. Res Eng Des 28:153-184. https://doi.org/10. 1007/s00163-016-0226-3

15. Ruckpaul A, Kriltz A, Matthiesen S (2014) Using eye tracking to understand the engineering designers' behavior in synthesis-driven analyzing processes-experiences in study design. In: Meboldt M, Matthiesen S, Badke-Schaub P et al (eds) International Conference on Human Behavior in Design, vol 1

16. Thau S (2013) Heuristiken zur Analyse und Synthese technischer Systeme mit dem C\&C2-Ansatz auf Basis von Entwicklungsprojekten im industriellen Umfeld. In: Albers A (ed) Forschungsberichte IPEK. Dissertation, vol 66. Karlsruher Institut für Technologie (KIT), Karlsruhe

17. Daly SR, Yilmaz S, Christian JL et al (2012) Design heuristics in engineering concept generation. J Eng Educ 101(4):601-629. https://doi.org/10.1002/j.2168-9830.2012.tb01121.x

18. Yilmaz S, Seifert CM (2011) Creativity through design heuristics: a case study of expert product design. Des Stud 32(4):384-415. https://doi.org/10.1016/j.destud.2011.01.003

19. Yilmaz S, Daly SR, Seifert CM et al (2015) How do designers generate new ideas? Design heuristics across two disciplines. Des Sci. https://doi.org/10.1017/dsj.2015.4

20. Horn S, Hölz K, Schwabe M et al (2019) Experimentelle Untersuchung von Versagensvorgängen an Verbundankern mit einem InSitu-Versuchsmodell. Beton Stahlbetonbau 99(7):561. https://doi. org/10.1002/best.201900013

21. Uibel T (2012) Spaltverhalten von Holz beim Eindrehen von selbstbohrenden Holzschrauben. Dissertation. Karlsruher Institut für Technologie (KIT), Karlsruhe

22. Matthiesen S, Hölz K, Grauberger P (2017) Systemverständnis durch Analysemethoden. In: Krause D, Paetzold K, Wartzack S (eds) 28th Symposium Design for X, pp 263-274

23. Matthiesen S (2002) Ein Beitrag zur Basisdefinition des Elementmodells "Wirkflächenpaare \& Leitstützstrukturen" zum Zusammenhang von Funktion und Gestalt technischer Systeme. In: Albers A (ed) Forschungsberichte IPEK. Dissertation, vol 6. Universität Karlsruhe (TH), Karlsruhe

24. Matthiesen S, Wettstein A, Grauberger P (2018) Analysis of dynamic system behaviour using sequence modelling with the C\&CApproach-a case study on a power tool hammer mechanism. In: Ekströmer P, Schütte S, Ölvander J (eds) NordDesign 2018 Linköping

25. Rouse WB, Rouse SH (1983) Analysis and classification of human error. Ieee Trans Syst Man Cybern 13(4):539-549. https://doi.org/ 10.1109/TSMC. 1983.6313142

26. Pugh S (1991) Total design: integrated methods for successful product engineering. Addison-Wesley, Wokingham

27. Kollmann FFP, Côté WA (1968) Principles of Wood Science and Technology. Springer, Berlin Heidelberg

28. Ringhofer A, Brandner R, Schickhofer G (2015) Withdrawal resistance of self-tapping screws in unidirectional and orthogonal layered timber products. Mater Struct 48(5):1435-1447. https://doi. org/10.1617/s11527-013-0244-9

29. Hoelz K, Grauberger P, Matthiesen S (2020in) Investigation of failure behavior in the thread contact of wood screws during the pull-out process. J Struct Eng 146(10). https://doi.org/10.1061/ (ASCE)ST.1943-541X.0002784

30. Ulrich KT, Eppinger SD (2004) Product design and development, 3rd edn. McGraw-Hill, Bosten 